\title{
Association of National Institute Health Stroke Scale (NIHSS) Score on Admission with the Outcome of Acute Ischemic Stroke at Discharge from Hospital
}

\author{
A T M HASIBUL HASAN, ${ }^{1}$ KHAN REDZWAN HABIB, ${ }^{2}$ ELHAM NUZHAT, ${ }^{3}$ LILIAN CATHERENE GOMES ${ }^{4}$ \\ MOHAMMAD MURAD HOSSAIN, ${ }^{5}$ MD. TITU MIAH, 6 KHAN ABUL KALAM AZAD, ${ }^{7}$ MD. BILLAL ALAM ${ }^{8}$
}

\begin{abstract}
:
Objectives: To determines the association of National Institute of Health Stroke Scale (NIHSS) score on admission with outcome of acute ischemic stroke during discharge from hospital.

Materials \& Methods: This hospital based observational study was done in medicine department of Dhaka Medical College Hospital involving 50 patients diagnosed as ischemic stroke on admission. The diagnosis of stroke was established by the clinical presentation, neuroimaging (CT scan/MRI). They were thoroughly examined and assessed with NIHSS score at admission. All data were be collected by using a preformed data sheet and results were presented in standard method after statistical analysis.

Results: Most of the patients were elder than 60 years of age and mean age of the patients was $60.34( \pm 16 . I)$ years at onset with a range of 24 to 76 years. Male were II 6 (58\%) and female were 84 (42\%). Male to female ratio was I.4:I. Majority had hypertension (75.8\%) followed by physical inactivity (67\%), Diabetes (37.4\%), smoking (33\%), obesity (23.1\%), family H/O stroke (20.9\%) and dyslipideamia (15.4\%). Higher NIHS score was associated with poor outcome ( $p$ value <0.05).

Conclusion: Among the common risk factors, smoking, hypertension, diabetes and atrial fibrillation are associated with worse outcome at discharge. Similarly, higher NIHSS score at admission and high CCl is also associated with poor outcome.
\end{abstract}

Key words: National Institute Health Stroke Scale (NIHSS), acute ischemic stroke, discharge from hospital.

DOI: http://dx.doi.org// 0.3329/jom.v19i2.37226

\section{Introduction:}

Stroke is a major cause of death and of disability worldwide. ${ }^{1}$ The prevalence of stroke is 3 per 1000 above the age of forty in Bangladesh. ${ }^{2}$ Every year around 16.3 million people suffer from stroke worldwide, among which 11.2 million events occur

1. Registrar, Dept. of Neurology, Dhaka Medical College Hospital

2. Ex-Surveillance Medical Officer, World Health organization, Bangladesh

3. Indoor Medical Officer (Medicine), Dhaka Dental College \& Hospital

4. Medical Officer (Physical Medicine \& Rehabilitation), Bangabandhu Sheikh Mujib Medical University, Shahbag, Dhaka

5. Associate Professor, Dept. of Medicine, Dhaka Medical College Hospital

6. Professor of Medicine, Dhaka Medical College Hospital

7. Professor of Medicine and Principal, Dhaka Medical College

8. Professor of Medicine and Principal, Sir Salimullah Medical College and Mitford Hospital

Corresponding author: Dr ATM Hasibul Hasan, Registrar, Department of Neurology, Dhaka Medical College Hospital. Email: parag007us@gmail.com.

Received: 05 September 2017;

Accepted: 12 April, 2018 in developing countries like ours and about 5.8 million people die of stroke, the two third of which occurs in developing nations ${ }^{3}$. Studies have reported that around 64.5 million stroke survivors are living with varying degree of disability. ${ }^{3}$ This morbidity burden is projected to raise about two folds causing 61 million (Disability Adjusted Life Year) DALY lost in 2020 than in 1990.4

Stroke severity on admission is a powerful determinate of functional outcomes in acute ischemic stroke. ${ }^{5-7}$ The National Institutes of Health Stroke Scale (NIHSS), which is a validated tool for assessing the initial stroke severity, has been shown to predict mortality in acute ischemic stroke in several prior studies. ${ }^{6-12}$ The National Institutes of Health Stroke Scale (NIHSS) is a useful tool for healthcare providers to objectively measure the impairment caused by a stroke. The NIHSS is composed of 11 items, each of which scores a specific ability between a 0 and 4 . For each item, a score of 0 typically indicates normal function in that specific ability, while a higher score is indicative of some level of impairment. The individual scores from each item are summed in order to calculate a patient's total NIHSS score. The maximum possible score is 42 , with the minimum score being a 0 . The NIHSS is 
a well validated and commonly used stroke impairment scale that sums the scores from individual elements of the neurological examination to provide an overall stroke impairment score. ${ }^{13-14}$ The Modified Rankin Scale (MRS) ${ }^{12}$ is widely used as a functional outcome measure in stroke.

Though there studies that denoted the co-morbid conditions among Bangladeshi patients with stroke, ${ }^{2}$ none has scientifically measured the effect of admission NIHS score with outcome of stroke among these patients. So, this study will help to ascertain the relationship between NIHS score and short term outcome of ischemic stroke among Bangladeshi patients.

\section{Materials \& Methods:}

This Hospital based cohort type of observation study was carried out in Dhaka Medical College Hospital, Dhaka from January 2015 to June 2015 involving 50 patients admitted in medicine and neurology department for acute ischemic stroke. We included patients of both sexes aged 20 years or above, with clinical sign symptoms of acute stroke admitted within 24 hours of onset and confirmed by CT scan who were examined and registered in the study procedure within 24 hour of hospital admission and stayed at hospital at least for 7 days if alive. We excluded any patient with TIA or intracerebral hemorrhage. A Semi-structured questionnaire was formed that include all the variables of interest. This questionnaire was used for collection of information on admission vital status, co-morbidities and later on the outcome of the patients.

\section{Ethical assurances for protection of human rights}

Written informed consent was taken from each patient. Prior to consent they were explained the aim and purpose of the study. Confidentiality was assured and anonymity was maintained; no participants were identified in any report or publication under this study. The study was approved by the ethical review committee of Dhaka Medical College \& Hospital.

\section{Data processing \& analysis}

After collection of information, these data were checked, verified for consistency and edited for finalized result. After editing and coding, the coded data were entered directly into the computer by using SPSS/PC software. The results were presented in tables and graphs. Chi-square test was performed and compared at $5 \%$ level of significance $(p<0.05)$.

\section{Results:}

This hospital based study involved a cohort 50 stroke patients admitted in Dhaka Medical College Hospital between January 2015 and June 2015. Majority of the patients (70\%) were 50 years or older with a mean age of $60.34( \pm 16.1)$ years (Table I). There was a slight male predominance with a male to female ratio of 1.4: 1 (Figure 1). Majority had hypertension (75.8\%) followed by physical inactivity (67\%), Diabetes (37.4\%), smoking (33\%), obesity (23.1\%), family H/O stroke (20.9\%) and dyslipideamia (15.4\%). Only 6.6\% were alcoholic and $4.4 \%$ had atrial fibrillation (Figure 2). Eight patients had NIHS score $<5$ and all of them had mRS score less than $<3$. Those with higher NIHS score $(\geq 5)$ had more patients with higher mRS score at discharge. The difference was also significant (Table II).

Table I

Distribution of patients by age at onset $(n=50)$

\begin{tabular}{lcc}
\hline Age group (Years) & Frequency & Percentage \\
\hline $21-30$ & 02 & 4.0 \\
$31-40$ & 04 & 8.0 \\
$41-50$ & 09 & 18.0 \\
$51-60$ & 13 & 26.0 \\
$>60$ & 22 & 44.0 \\
\hline Total & 50 & 100.0 \\
Mean $( \pm \mathrm{SD})$ & $60.34( \pm 16.1)$ years & $24-76$ years \\
\hline
\end{tabular}

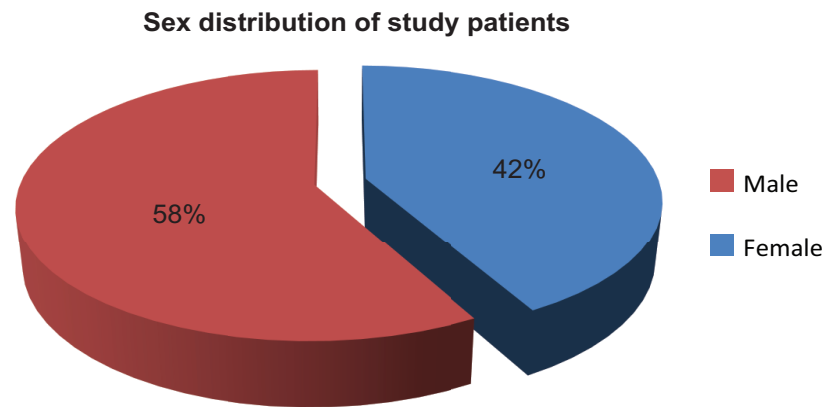

Figure 1: Sex distribution of the study patients $(n=50)$

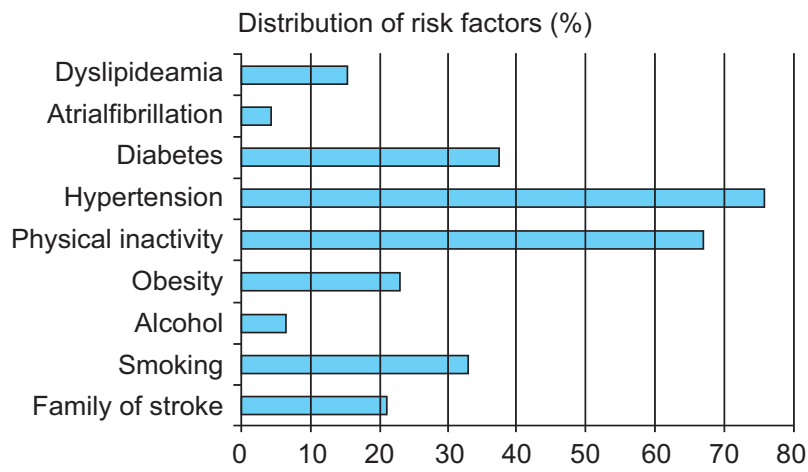

Figure 2: Distribution of risk factors among the study patients $(n=50)$. 
Table II

Association of risk factors with outcome of stroke at discharge $(n=50)$

\begin{tabular}{lcccc}
\hline Risk Factors & \multicolumn{3}{c}{$\begin{array}{c}\text { Modified Rankin Scale Score } \\
\text { (Number) }\end{array}$} & $\begin{array}{c}\text { P } \\
\text { value* }\end{array}$ \\
& $<3$ & $3-5$ & $>6$ & \\
\hline Family H/O stroke & 02 & 07 & 01 & $>0.05$ \\
Smoking & 05 & 10 & 01 & $<0.05$ \\
Alcohol & 01 & 03 & 0 & $>0.05$ \\
Obesity & 01 & 04 & 02 & $>0.05$ \\
Physical Inactivity & 13 & 13 & 04 & $>0.05$ \\
Hypertension & 10 & 23 & 06 & $<0.05$ \\
Diabetes & 04 & 13 & 1 & $<0.05$ \\
Atrial fibrillation & 00 & 00 & 02 & $<0.05$ \\
Dyslipidaemia & 04 & 03 & 01 & $>0.05$ \\
\hline
\end{tabular}

*Chi square test

Table III

Association of Charlson Co-morbidity Index (CCI) score level with outcome of stroke at discharge $(n=50)$

\begin{tabular}{lcccc}
\hline $\begin{array}{l}\text { Charlson Co-morbidity } \\
\text { Index (CCI) score }\end{array}$ & \multicolumn{3}{c}{$\begin{array}{c}\text { Modified Rankin Scale } \\
\text { Score(Number) }\end{array}$} & $\begin{array}{c}\text { P } \\
\text { value* }\end{array}$ \\
\hline$<5$ & $<3$ & $3-5$ & $>6$ & \\
$5-10$ & 18 & 06 & 03 & $<0.05$ \\
$>10$ & 06 & 12 & 02 & \\
\hline
\end{tabular}

*Chi square test

Table IV

Association of National Institute of Health Stroke Scale (NIHSS) score level with outcome of stroke at discharge $(n=50)$

\begin{tabular}{lrccc}
\hline $\begin{array}{l}\text { National Institute of } \\
\text { Health StrokeScale }\end{array}$ & \multicolumn{2}{c}{$\begin{array}{c}\text { Modified Rankin } \\
\text { Scale Score } \\
\text { (NIHSS) score }\end{array}$} & $\begin{array}{c}\text { P } \\
\text { (Number) }\end{array}$ & value* \\
\hline Minor(1-4) & 08 & 00 & 00 & $<0.05$ \\
Moderate (5-15) & 13 & 13 & 01 & \\
Moderate-Severe (16-20) 03 & 05 & 04 & \\
Severe (21-42) & 00 & 02 & 01 & \\
\hline
\end{tabular}

*Chi square test

\section{Discussion:}

This hospital based cohort study was done in Dhaka Medical College Hospital involving fifty acute ischemic stroke patients. In this study, presence of several risk factors, higher co-morbidities and higher NIHSS score was found to have negative impact on hospital outcome of acute ischemic stroke patients at discharge.

The NIHSS has been shown to be predictive of a variety of stroke functional outcomes. ${ }^{7-10}$ Stroke severity estimated by NIHSS has also been shown to be predictive of mortality after acute ischemic stroke. ${ }^{9-13}$ One single hospital based study in Taiwan involving three hundred and sixty ischemic stroke patients have shown that NIHSS score is the strongest predictor of 3-month mortality, with an odds ratio of 1.17 (95\% CI, 1.12-1.22) per point. ${ }^{10}$ Another study analyzed 479 patients admitted to a single center in Switzerland reporting that advanced age, and high NIHSS were the only independent predictor of 30-day mortality. ${ }^{9}$ A study involving seven centers in Germany found NIHSS obtained within the first 6 hours of admission to be highly predictive of 100-day survival (c-statistic 0.86). ${ }^{11}$ But the unique nature of our study is that we have evaluated the patients at discharge which was not done in none of these studies. Our study illustrates a strong relationship among the stroke severity at admission and outcome of patients at discharge.

There were several limitations in this study. First of all, this study measured a very short term outcome of acute stroke patients during hospital stay. A long term study is required for making further comments. Secondly, the sample size was relatively small and the period of time of the study was short. Moreover, the study was a single center study which may not reflect the actual epidemiological and clinical picture.

\section{Conclusions:}

Patients with acute ischemic stroke may have several comorbidities. Higher stroke severity as estimated by admission NIHSS score is associated with poor outcome at discharge from hospital.

\section{Conflict of interest: None.}

\section{References:}

1. Kumar P, Clark M, Editors. Kumar \& Clark Clinical Medicine. $7^{\text {th }}$ edition. Spain: Elsevier limited; 2009:1126.

2. Mohammad QD, Habib M, Hoque A, Alam B, Haque B, Hossain $\mathrm{S}$ et al. Prevalence of stroke above forty years. Mymenshingh Med J 2011;20(4):640-4.

3. Truelsen T, Bonita R. The worldwide burden of stroke: current status and future projections. In: Fisher M, editor. Handbook of Clinical Neurology, Elsevier B.V. 2009; 92:327336. 
4. Mackay J, Mensah GA. Global Burden of Stroke. In : The atlas of Heart Disease and Stroke (Part-three). World Health Organization: pp-50-51.

5. Adams HP Jr, Davis PH, Leira EC, Chang KC, Bendixen BH, Clarke WR, Woolson RF, Hansen MD. Baseline NIH Stroke Scale score strongly predicts outcome after stroke: a report of the Trial of ORG 10172 in Acute Stroke Treatment (TOAST). Neurology. 1999;53:126-131.

6. Dhamoon MS, Moon YP, Paik MC, Boden-Albala B, Rundek T, Sacco RL, Elkind MS. Long-term functional recovery after first ischemic stroke: the Northern Manhattan Study. Stroke. 2009;40:2805-2811.

7. Johnston KC, Connors AF Jr, Wagner DP, Knaus WA, Wang $\mathrm{X}$, Haley EC Jr. A predictive risk model for outcomes of ischemic stroke. Stroke. 2000;31:448-455.

8. Henon H, Godefroy O, Leys D, Mounier-Vehier F, Lucas C, Rondepierre P, Duhamel A, Pruvo JP. Early predictors of death and disability after acute cerebral ischemic event. Stroke. 1995;26:392-398.
9. Nedeltchev K, Renz N, Karameshev A, Haefeli T, Brekenfeld C, Meier N, Remonda L, Schroth G, Arnold M, Mattle HP. Predictors of early mortality after acute ischaemic stroke. Swiss Med Wkly. 2010;140:254-259.

10. Chang KC, Tseng MC, Tan TY, Liou CW. Predicting 3month mortality among patients hospitalized for first-ever acute ischemic stroke. J Formos Med Assoc. 2006; 105:310 317.

11. Weimar C, Konig IR, Kraywinkel K, Ziegler A, Diener HC. Age and National Institutes of Health Stroke Scale score within 6 hours after onset are accurate predictors of outcome after cerebral ischemia: development and external validation of prognostic models. Stroke. 2004;35:158-162.

12. Van Swieten, J. C., Koudstaal, P. J., Visser, M. C., Schouten, H. J. A., \& van Gijn, J. Interobserver agreement for the assessment of handicap in stroke patients. Stroke 1988;19:604-607.

13. Giaquinto S. Comorbidity in post-stroke rehabilitation. Eur J Neurol 2003;10:235-238. 